\title{
ARTICLE
}

\section{Separation of Y(III) and Sr(II) from acid solutions by extraction chromatography using HDEHP-impregnated adsorbent and its medical application}

\author{
Seong-Yun $\mathrm{Kim}^{*}$ and Tatsuya Ito \\ Department of Quantum Science and Energy Engineering, Tohoku University, Aramaki-Aza-Aoba 6-6-01-2, Sendai, 980-8579, Japan
}

The selective separation and recovery of $\mathrm{Y}$ (III) from $\mathrm{Sr}$ (II) were investigated using a macroporous silica/polymer composite $\left(\mathrm{SiO}_{2}-\mathrm{P}\right)$ supported bis(2-ethylhexyl)phosphate (HDEHP) and 1-dodecanol (dodec) impregnated adsorbent (HDEHP+dodec) $/ \mathrm{SiO}_{2}-\mathrm{P}$. The adsorption and separation of $\mathrm{Y}$ (III) and $\mathrm{Sr}(\mathrm{II})$ in $\mathrm{HNO}_{3}$ and $\mathrm{HCl}$ solutions onto the adsorbent were investigated by batch and column methods. The adsorbent showed a higher adsorption affinity to $\mathrm{Y}(\mathrm{III})$ than $\mathrm{Sr}(\mathrm{II})$. The adsorption of $\mathrm{Y}$ (III) decreased as the acidity of the solution increased. The adsorption of Y(III) could be expressed by the Langmuir adsorption model and was governed by chemisorption. In addition, the adsorption thermodynamic parameters of Y(III) were calculated using the van't Hoff equation, and the reaction was found to be exothermic. In column experiments, a relatively satisfactory chromatographic separation of $\mathrm{Y}$ (III) from a $\mathrm{Sr}$ (II)-Y(III) mixed solution was obtained using the adsorbent packed column.

Keywords: yttrium, strontium, HDEHP impregnated resin, extraction chromatography

\section{Introduction}

The partitioning of high-level liquid waste (HLLW) produced from the PUREX processing of spent nuclear fuel is thought to be a favorable method from the viewpoints of minimizing long-term radiological risk and radioactive waste accumulation [1]. In the utilization of large amounts of ${ }^{90} \mathrm{Sr}$ separated from HLLW $(\sim 1.1$ $\mathrm{kg} / 1 \mathrm{tHU}, 45 \mathrm{GWd} / \mathrm{t}),{ }^{90} \mathrm{Y}$, a daughter nuclide of ${ }^{90} \mathrm{Sr}$ $\left(T_{1 / 2}=28.8 \mathrm{y}\right)$, is expected to separate from the ${ }^{90} \mathrm{Sr}-{ }^{90} \mathrm{Y}$ group; ${ }^{90} \mathrm{Y}$ is an important radionuclide known for its therapeutic application in the medical field. It is a pure beta-emitter with no associated gamma rays and decays to stable daughter nuclide ${ }^{90} \mathrm{Zr}$. This radioisotope is particularly useful owing to its emitted beta particles, which have a maximum energy of $2.28 \mathrm{MeV}$ and a short half-life $\left(T_{1 / 2}=64.1 \mathrm{~h}\right)$. For these reasons, ${ }^{90} \mathrm{Y}$ has recently been clinically used for internal radiation therapy [2]. In the nuclear decay process, ${ }^{90} \mathrm{Y}$ is generated from the beta decay of ${ }^{90} \mathrm{Sr}$, and the decay line of ${ }^{90} \mathrm{Sr} /{ }^{90} \mathrm{Y}$ is shown below:

$$
\left.{ }^{90} \mathrm{Sr} \frac{\beta^{-}(0.54 \mathrm{MeV})}{28 \text { year }}{ }^{90} \mathrm{Y} \frac{\beta^{-}(2.28 \mathrm{MeV})}{64 \text { hour }}{ }^{90} \mathrm{Zr} \text { (stable }\right)
$$

Therefore, it can be considered that ${ }^{90} \mathrm{Y}$ needs to be separated and purified from ${ }^{90} \mathrm{Y}-{ }^{90} \mathrm{Sr}$ mixtures before being used for radiotherapy. For therapeutic application in nuclear medicine, the basic requirements for ${ }^{90} \mathrm{Y}-{ }^{90} \mathrm{Sr}$ separation are a high yield of the daughter radionuclide ${ }^{90} \mathrm{Y}$ in minimal volumes and high radionuclidic purity

*Corresponding author. Email: kim@qse.tohoku.ac.jp with low breakthrough of the parent ${ }^{90} \mathrm{Sr}$. For this purpose, numerous chemical separation methods have been reported for the separation of ${ }^{90} \mathrm{Y}$ from ${ }^{90} \mathrm{Y}-{ }^{90} \mathrm{Sr}$ mixtures, such as precipitation [3], solvent extraction [4], ion exchange [5], use of liquid membranes [6], and extraction chromatography [7].

In this study, we have attempted to load the bis(2-ethylhexyl)phosphate (HDEHP) extractant and a molecular modifier, 1-dodecanal (dodec), into macroporous silica/styrene-divinylbenzene copolymer composite particles $\left(\mathrm{SiO}_{2}-\mathrm{P}\right)$, named as $(\mathrm{HDEHP}+$ dodec $) / \mathrm{SiO}_{2}-\mathrm{P}$, for the separation of $\mathrm{Y}(\mathrm{III})$ from a $\mathrm{Sr}(\mathrm{II})-\mathrm{Y}(\mathrm{III})$ mixed solution. The present article deals with the preparation of the HDEHP-loaded adsorbent and the characterization, adsorption equilibrium, kinetic modeling, and elution properties of Y(III) with a fixed-bed column.

\section{Experimental}

The (HDEHP + dodec $) / \mathrm{SiO}_{2}-\mathrm{P}$ adsorbent was synthesized by loading HEDHP and dodec into $\mathrm{SiO}_{2}-\mathrm{P}$ support based on impregnation method [7]. Dissolved HDEHP and dodec in dichloromethane were mixed with the washed with methanol and dried $\mathrm{SiO}_{2}-\mathrm{P}$, and the solvent was removed by evaporation under reduced-pressure. After drying in a vacuum, the adsorbent was obtained. The compositions of the adsorbent under the preparation conditions were HEDHP: $25 \mathrm{wt} \%$, dodec: $25 \mathrm{wt} \%$, and $\mathrm{SiO}_{2}-\mathrm{P}: 50 \mathrm{wt} \%$.

The adsorption of $\mathrm{Sr}(\mathrm{II})$ and $\mathrm{Y}(\mathrm{III})$ ions onto the adsorbent was examined by batch method. Dry 
adsorbent $(0.20 \mathrm{~g})$ was mixed in a glass flask with 4.0 $\mathrm{cm}^{3}$ liquid phase up to 5 hours in a thermostatic shaking bath. The solutions contained $10 \mathrm{mM}$ of Sr(II) and Y(III) in different concentrations of $\mathrm{HNO}_{3}$ or $\mathrm{HCl}$. After the resultant mixture was separated by vacuum filtration, the concentrations of metal ions in the liquid phase were determined by inductively coupled plasma-atomic emission spectroscopy (ICP-AES). The adsorbed amount $\left(q, \mathrm{mg} \cdot \mathrm{g}^{-1}\right)$ of $\mathrm{Y}(\mathrm{III})$ was calculated as follows:

$$
q=\frac{\left(C_{0}-C_{\mathrm{t}}\right) \times V}{1000 \times m}
$$

where $C_{0}$ is the initial concentration of Y(III) and $C_{\mathrm{t}}$ is the concentration after a certain time in the liquid phase $\left(\mathrm{mg} \cdot \mathrm{L}^{-1}\right) . V$ is the initial solution volume $(\mathrm{mL})$, and $m$ is the mass of dry adsorbent $(\mathrm{g})$, or this can be expressed as the uptake ratio $(R, \%)$

$$
R=\frac{\left(C_{0}-C_{\mathrm{t}}\right)}{C_{0}} \times 100
$$

The distribution coefficient $\left(K_{\mathrm{d}}, \mathrm{cm}^{3} \cdot \mathrm{g}^{-1}\right)$ of $\mathrm{Y}(\mathrm{III})$ between an aqueous and a solid phase was obtained from the following equation:

$$
K_{\mathrm{d}}=\frac{\left(C_{0}-C_{\mathrm{e}}\right)}{C_{\mathrm{e}}} \times \frac{V}{m}
$$

where $C_{\mathrm{e}}$ is the concentration at equilibrium $\left(\mathrm{mg} \cdot \mathrm{L}^{-1}\right)$.

The separation of metal ions with the adsorbent was evaluated using a column experiment for chromatographic separation. Dry adsorbent (4.0 g) was packed into a glass column, and the experiment was performed at $25{ }^{\circ} \mathrm{C}$ by circulating thermostatic water through the column jacket. $10 \mathrm{~cm}^{3}$ of the $\mathrm{Sr}$ (II)-Y(III) mixed solution was fed into the column by tube pump at flow rate $0.5 \mathrm{~cm}^{3} \cdot \mathrm{min}^{-1}$. Subsequently, $30 \mathrm{~cm}^{3}$ of wash solution and $100 \mathrm{~cm}^{3}$ of eluent were also supplied. The effluent from the column was collected by fraction collector and the concentration of metal ions in each fraction were analyzed by ICP-AES.

\section{Results and discussion}

\subsection{Batch adsorption behavior}

To investigate the adsorption mechanism, the rate constants for the adsorption of $\mathrm{Y}$ (III) onto the $(\mathrm{HDEHP}+$ dodec $) / \mathrm{SiO}_{2}-\mathrm{P}$ adsorbent were calculated using the equation of a pseudo-second order mechanism [8] from the results in Figure 1. This adsorption model assumes that the adsorption rate is controlled by chemisorption and that the adsorption capacity is proportional to the number of active sites on the adsorbent. The adsorption model is shown as follows

$$
\frac{t}{q_{t}}=\frac{1}{k_{2} q_{\mathrm{e}}^{2}}+\frac{t}{q_{\mathrm{e}}}
$$

where $q_{\mathrm{t}}$ and $q_{\mathrm{e}}$ are the amounts of Y(III) adsorbed at time $t(\mathrm{hr})$ or at equilibrium $\left(\mathrm{mg} \cdot \mathrm{g}^{-1}\right)$ and $k_{2}$ is the pseudo-second-order rate constant for adsorption $\left(\mathrm{g} \cdot \mathrm{mg}^{-1} \cdot \mathrm{h}^{-1}\right)$.

As shown in Figure 1, plots of $t / q_{\mathrm{t}}$ vs. $t$ provide two relatively good straight lines for the tested Y(III), indicating that the results fit well with the pseudo-second order model and the rate-controlling step of this adsorption process is governed by chemisorption. From the analysis, the $q_{\mathrm{e}}$ values for Y(III) were determined to be 17.2 and $15.8 \mathrm{mg} \cdot \mathrm{g}^{-1}$. These calculated $q_{\mathrm{e}}$ were found to be similar to the experimental values of 16.6 and $15.4 \mathrm{mg} \cdot \mathrm{g}^{-1}$, respectively.

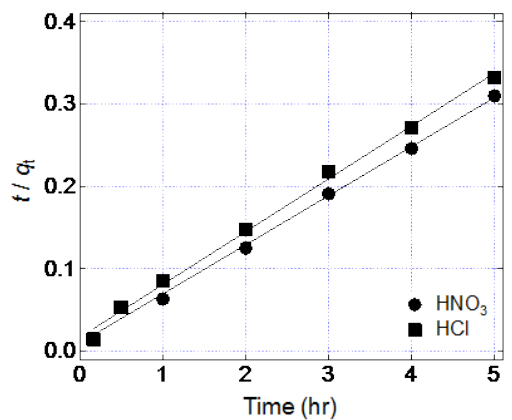

Figure 1. Plot of the pseudo-second order model for Y(III) adsorption onto $(\mathrm{HDEHP}+$ dodec $) / \mathrm{SiO}_{2}-\mathrm{P}$ adsorbent. $\mathrm{V} / \mathrm{m}: 20$ $\mathrm{cm}^{3}$; [Y(III)]: $10 \mathrm{mM} ; 25^{\circ} \mathrm{C}$.

To understand the effect of the acid concentration, the adsorption of the $\mathrm{Sr}(\mathrm{II})$ and $\mathrm{Y}$ (III) onto the adsorbent for acid solution concentrations in the range 0.001 to 5 $\mathrm{M}\left(\mathrm{M}=\mathrm{mol} \cdot \mathrm{dm}^{-3}\right)$ was investigated at $25^{\circ} \mathrm{C}$.

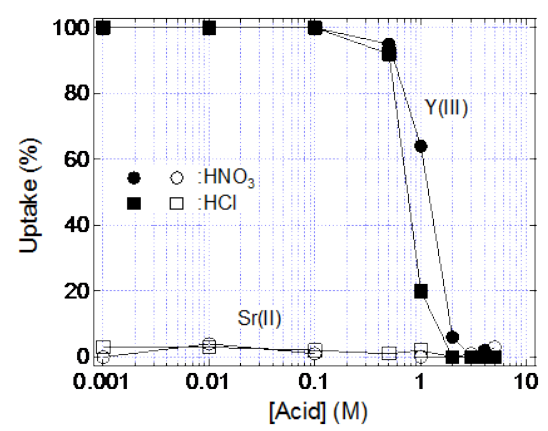

Figure 2. Effect of acid concentration on uptake of $\mathrm{Sr}(\mathrm{II})$ and Y(III) onto (HDEHP+dodec) $/ \mathrm{SiO}_{2}-\mathrm{P}$ adsorbent. $V / m: 20 \mathrm{~cm}^{3}$; [Sr(II), Y(III)]: $10 \mathrm{mM} ; 25^{\circ} \mathrm{C}$.

As shown in Figure 2, the adsorbent showed a strong adsorption affinity to Y(III) and a weak adsorption to $\mathrm{Sr}(\mathrm{II})$. On the other hand, the uptake ratios of $\mathrm{Y}$ (III) decreased as the acidity of $\mathrm{HNO}_{3}$ and $\mathrm{HCl}$ solutions increased. From the literatures on studies on the solvent extraction of rare-earth elements from acidic solution, deprotonation of dialkylphosphinic acids was necessary to extract the trivalent ions [9]. Therefore, an increase of acidity was considered to interfere the adsorption.

The high adsorption affinity for Y(III) indicates that selective separation of $\mathrm{Y}$ (III) from a $\mathrm{Sr}(\mathrm{II})-\mathrm{Y}(\mathrm{III})$ mixture by the $(\mathrm{HDEHP}+$ dodec $) / \mathrm{SiO}_{2}-\mathrm{P}$ is possible in low-acid solution.

\subsection{Equilibrium adsorption isotherm models}

Besides the adsorption behavior, the liquid phase is important in determining the maximum adsorption capacity $\left(q_{\max }, \mathrm{mmol} \cdot \mathrm{g}^{-1}\right)$, which is an important parameter in the adsorption process. Adsorption 
equilibrium data is important in clarifying the adsorption of Y(III) on the (HDEHP+dodec) $/ \mathrm{SiO}_{2}-\mathrm{P}$ in $\mathrm{HNO}_{3}$ and $\mathrm{HCl}$ solutions. In this study, three important isotherm models are selected to fit the experimental data, which are the Langmuir, Freundlich and Dubinin-Radushkevich isotherm models [10].

Langmuir:

Non-linear form

$$
q_{\mathrm{e}}=\frac{q_{\mathrm{max}} b C_{\mathrm{e}}}{1+b C_{\mathrm{e}}}
$$

Linear form

$$
\frac{C_{\mathrm{e}}}{q_{\mathrm{e}}}=\frac{C_{\mathrm{e}}}{q_{\max }}+\frac{1}{b \cdot q_{\max }}
$$

Freundlich:

Non-linear form

$$
q_{\mathrm{e}}=K_{\mathrm{f}} C_{\mathrm{e}}^{\left(1 / n_{\mathrm{f}}\right)} \quad \log q_{\mathrm{e}}=\log K_{\mathrm{f}}+\frac{1}{n_{\mathrm{f}}} \log C_{\mathrm{e}}
$$

Dubinin-Radushkevich:

$$
\begin{array}{lcc}
\text { Non-linear form } & \text { Linear form } \\
q_{\mathrm{e}}=\ln q_{\max }-\exp \left(-\beta \varepsilon^{2}\right) & \ln q_{e}=\ln q_{\max }-\beta \varepsilon^{2} \\
\varepsilon=R T \ln \left(1+\frac{1}{C_{\mathrm{e}}}\right) & \text { (9) } & E=\frac{1}{\sqrt{2 \beta}}
\end{array}
$$

where, $b, 1 / n_{\mathrm{f}}, K_{\mathrm{f}}$ and $\beta$ are the Langmiuir constant $\left(\mathrm{L} \cdot \mathrm{mmol}^{-1}\right)$, the Freundlich isotherm exponent constant related to the adsorption intensity, the Freundlich constan $\left(\mathrm{mmol} \cdot \mathrm{g}^{-1}\right)$ and the Dubinin-Radushkevich constant $\left(\mathrm{mol}^{2} \cdot \mathrm{kJ}^{-2}\right)$, respectively. $R, T$ and $E$ represent the gas constant $\left(8.314 \mathrm{~J} \cdot \mathrm{mol}^{-1} \cdot \mathrm{K}^{-1}\right)$, temperature $(\mathrm{K})$ and the mean adsorption energy $\left(\mathrm{kJ} \cdot \mathrm{mol}^{-1}\right)$.
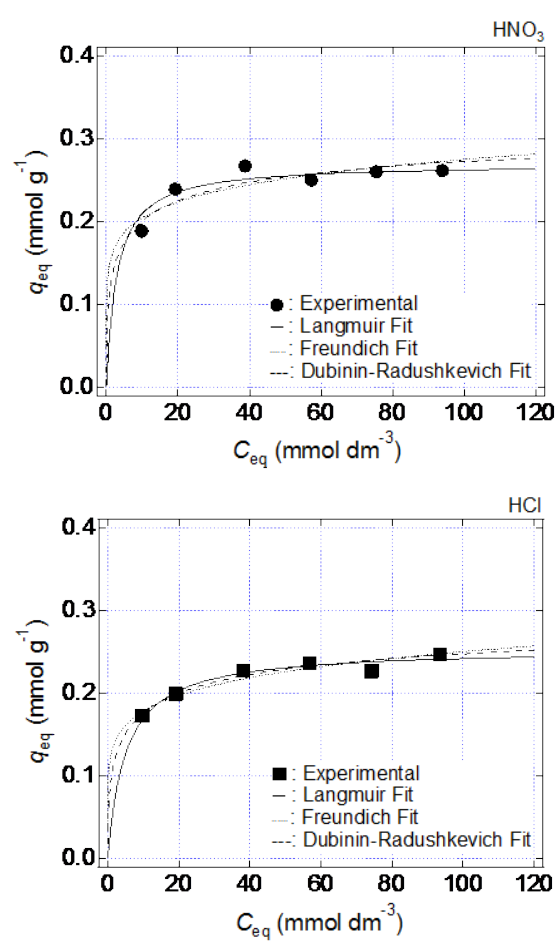

Figure 3. Non-linear isotherm plots of $\mathrm{Y}(\mathrm{III})$ on $(\mathrm{HDEHP}+\operatorname{dodec}) / \mathrm{SiO}_{2}-\mathrm{P}$ adsorbent.

Figure 3 shows Y(III) adsorption data for the adsorbent and the non-linear fits, and the calculated parameters are summarized in Table 1. The isotherms were obtained for a wide range of Y(III) concentrations in the initial mixture with $0.5 \mathrm{M} \mathrm{HNO}_{3}$ or $\mathrm{HCl}$ at $25^{\circ} \mathrm{C}$.
The equilibrium adsorbed amounts of Y(III) approached a constant value with increasing concentration.

The maximum adsorption amounts are 0.27 and 0.25 mmol $\cdot \mathrm{g}^{-1}$ for $\mathrm{HNO}_{3}$ and $\mathrm{HCl}$, respectively. The $R^{2}$ values of these straight lines indicate that these adsorption processes could be expressed by the Langmuir monomolecular layer adsorption mode.

Table 1. Isotherm parameters for the adsorption of Y(III).

\begin{tabular}{llcc}
\hline Models & & $\mathrm{HNO}_{3}$ & $\mathrm{HCl}$ \\
\hline Langmuir & $q_{\max }$ & 0.270 & 0.254 \\
& $b$ & 0.346 & 0.200 \\
Freundlich & $R^{2}$ & 1.00 & 1.00 \\
& $K_{\mathrm{f}}$ & 0.152 & 0.127 \\
Dubinin-Radushkevich & $1 / n_{\mathrm{f}}$ & 0.129 & 0.147 \\
& $R^{2}$ & 0.73 & 0.92 \\
& $q_{\max }$ & 0.305 & 0.281 \\
& $K$ & -0.00320 & -0.00358 \\
& $E$ & 12.5 & 11.8 \\
& $R^{2}$ & 0.80 & 0.95 \\
\hline
\end{tabular}

\subsection{Effect of temperature on Y(III) adsorption}

To understand the temperature effect, the adsorption of $\mathrm{Y}$ (III) onto (HDEHP+dodec) $/ \mathrm{SiO}_{2}-\mathrm{P}$ adsorbent in 0.5 $\mathrm{M} \mathrm{HNO}_{3}$ and $\mathrm{HCl}$ solution were investigated at different temperature. The corresponding plots of $\ln K_{\mathrm{d}}$ versus $1 / T$ provide were depicted in Figure 4. The $\ln K_{\mathrm{d}}$ value showed significant decrease with the increase of temperature, reflecting that adsorption process were exothermic reaction and the adsorption of Y(III) was decreased by temperature elevation.

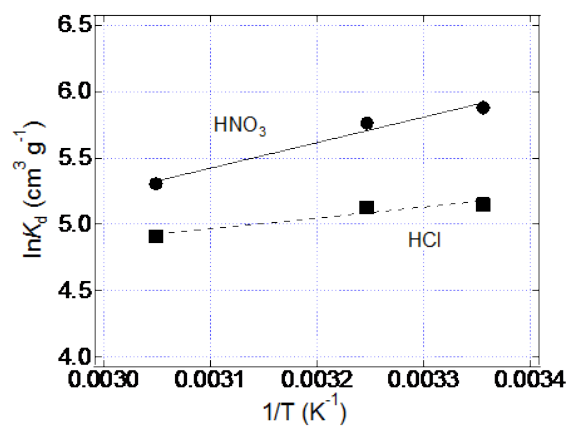

Figure 4. Effect of solution temperature on the $K_{\mathrm{d}}$ value of Y(III) adsorption on adsorbents.

Table 2. Thermodynamic parameters for Y(III) adsorption onto the $(\mathrm{HDEHP}+$ dodec $) / \mathrm{SiO}_{2}-\mathrm{P}$ adsorbent

\begin{tabular}{ccc}
\hline & $\mathrm{HNO}_{3}$ & $\mathrm{HCl}$ \\
\hline$\Delta H^{0}\left(\mathrm{~kJ} \cdot \mathrm{mol}^{-1}\right)$ & -16.0 & -6.81 \\
$\Delta S^{0}\left(\mathrm{~J} \cdot \mathrm{K}^{-1} \mathrm{~mol}^{-1}\right)$ & -0.00442 & 0.0202 \\
$R^{2}$ & 0.972 & 0.929 \\
$\mathrm{Temp}(\mathrm{K})$ & $-\Delta G^{0}\left(\mathrm{~kJ} \cdot \mathrm{mol}^{-1}\right)$ & $-\Delta G^{0}\left(\mathrm{~kJ} \cdot \mathrm{mol}^{-1}\right)$ \\
\hline 298 & -14.7 & -12.8 \\
303 & -14.6 & -13.0 \\
323 & -14.5 & -13.4 \\
\hline
\end{tabular}

In order to gain insight into the thermodynamic nature of the adsorption process, several thermodynamic parameters for the adsorption system were calculated [11] and summarized in Table 2. In Table 2, the obtained the negative values of $\Delta G^{0}$ for the 
$(\mathrm{HDEHP}+$ dodec $) / \mathrm{SiO}_{2}-\mathrm{P}$ adsorbent indicate spontaneous adsorption. $\Delta H^{0}$ was negative for the adsorbent, which indicates that the adsorption processes are endothermic. Furthermore, the negative values of $\Delta S^{0}$ indicate increasing randomness in the solid/solution interface during the adsorption process.

\subsection{Column separation}

The efficient separation of Y(III) from $\mathrm{Sr}$ (II) by means of extraction chromatography using the $(\mathrm{HDEHP}+$ dodec $) / \mathrm{SiO}_{2}-\mathrm{P}$ is expected from the large difference in their uptake shown in Figure 2. For the separation of Y(III) and $\mathrm{Sr}(\mathrm{II})$, the elution curves in the effluent are illustrated in Figure 5.
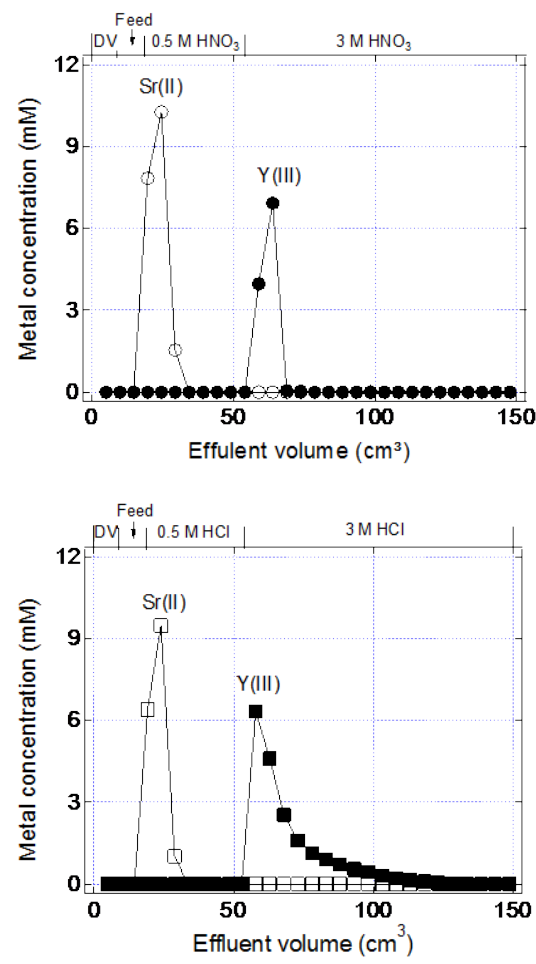

Figure 5. Column separation results of $\mathrm{Sr}(\mathrm{II})$ and $\mathrm{Y}(\mathrm{III})$ from $0.5 \mathrm{M} \mathrm{HNO}_{3}, \mathrm{HCl}$ solution using the $(\mathrm{HDEHP}+\operatorname{dodec}) / \mathrm{SiO}_{2}-\mathrm{P}$ adsorbent.

As shown in the figure, $\operatorname{Sr}($ II) showed a very weak adsorption by the adsorbent and broke through the column along with $0.5 \mathrm{M} \mathrm{HNO}_{3}$ and $\mathrm{HCl}$ solution. The adsorption behavior of $\mathrm{Sr}(\mathrm{II})$ during column separation is similar to that in the batch experiment. Subsequently, with a supplement of $3 \mathrm{M} \mathrm{HNO}_{3}$ and $\mathrm{HCl}$ solution to the column, the Y(III), witch strongly adsorbed onto the adsorbent, was finally eluted out. In terms of the mass balance, the recovery of $\mathrm{Y}$ (III) was calculated as 100 $\mathrm{wt} \% \quad\left(\mathrm{HNO}_{3}\right)$ and $96.2 \quad \mathrm{wt} \% \quad(\mathrm{HCl})$. Satisfactory partitioning and recovery of Y(III) from the Sr-Y group with the $(\mathrm{HDEHP}+$ dodec $) / \mathrm{SiO}_{2}-\mathrm{P}$ was thus achieved.

\section{Conclusion}

It was found that the adsorbent showed a strong adsorption affinity to $\mathrm{Y}$ (III) and a weak adsorption ability with $\operatorname{Sr}(\mathrm{II})$ under experimental conditions.
Kinetic data were successfully modeled using pseudo-second-order kinetics. This adsorption process could be expressed by the Langmuir model, and is governed by chemisorption. In the extraction chromatography experiments, the separation of Y(III) from a $\mathrm{Sr}$ (II)-Y(III) mixed solution was achieved successfully.

\section{Acknowledgements}

This work was supported by JSPS KAKENHI Grant Number $16 \mathrm{H} 02444$.

\section{References}

[1] Y. Ando and H. Takano, Estimation of LWR spent fuel composition, JAEAI-Reasearch 99-004 (1999) [in Japanese].

[2] L.A. Schulz and L.A. Bray, Solvent extraction recovery of byproduct ${ }^{137} \mathrm{Cs}$ and ${ }^{90} \mathrm{Sr}$ from $\mathrm{HNO}_{3}$ solutions-a technology review and assessment, Sep. Sci. Technol. 22 (1987), pp. 191-214.

[3] R. Salutsky and M. Kirly, Preparation and half-life of carrier-free yttrium-90. Anal. Chem. 27 (1955), pp. 567-569.

[4] J.S. Wike, C.E. Guyer, D.W. Ramey et al., Chemistry for commercial scale production of yttrium-90 for medical research, Appl. Radiation Isotopes, 41 (1990), pp. 861-865.

[5] T. Kawashima, Separation of carrier-free ${ }^{90} \mathrm{Y}$ from ${ }^{90} \mathrm{Sr}$ by cation exchange in a methanol-ammonium acetate medium, Int. J. Appl. Radiat. Isotop. 20 (1969), pp. 806-808.

[6] P.S. Dhami, P.W. Naik, N.L. Dudwadkar et al., Studies on the development of a two stage SLM system for the separation of carrier free ${ }^{90} \mathrm{Y}$ using KSM-17 and CMPO as carriers, Sep. Sci. Technol. 42 (2007), pp. 1107-1121.

[7] Y. Xu, S.-Y. Kim, T. Ito et al., Adsorption and separation behavior of yttrium and strontium in nitric acid solution by extraction chromatography using a macroporous silica-based adsorbent, $J$. Chromatography A, 1263 (2012), pp. 28-33.

[8] Y.S. Ho, W.T.Chiu, C.S. Hsu et al., Sorption of lead ions from aqueous solution using tree fern as a sorbent, Hydrometallurgy, 73 (2004), pp. 55-61.

[9] G.J. Lumetta, A.V. Gelis and G.F. Vandegrift, Review: Solvent systems combining neutral and acidic extractants for separating trivalent lanthanides from the transuranic elements, Solv. Extr. Ion Exch., 28 (2010), pp. 287-312.

[10]Y.S. Ho, J.F. Porter and G. McKay, Equilibrium isotherm studies for the sorption of divalent metal ions onto peat: copper, nickel and lead single component systems, Water Air and Soil Pollut., 141 (2002), pp. 1-33.

[11]A. Nilchi, R. Saberi, M. Moradi, H. Azizpour and R. Zarghami, Evaluation of AMP-PAN composite for adsorption of $\mathrm{Cs}+$ ions from aqueous solution using batch and fixed bed operations, J. Radioanal. Nucl. Chem. 292 (2012), pp. 609-617. 